\title{
ANOTACIONES SOBRE EL PRINCIPIO KANTIANO DE PUBLICIDAD
}

JAVIER DE LUCAS

UNIVERSIDAd de VALENCIA, ESPAŃ́

El examen de la formulación del principio de publicidad en Kant requiere una lectura atenta que excede con mucho las conocidas páginas de su escrito de 1795 sobre la Paz perpetua, en las que se encuentra enunciado. En realidad, hay que remontarse a la Critica de la razón pura (la 1a. edición, como es sabido, aparece en 1781) para encontrar los supuestos teóricos sobre los que se va a edificar tal principio, y para esto también es preciso recorrer los escritos "menores" de los años 1784 -Idea de una historia universal en sentido cosmopolita y ¿QQué es Ilustración?-, 1786 -Qué significa orientarse en el pensamiento y Comienzo presunto de la historia humana-, 1796 -Sobre el refrán: Esto puede ser verdad en teoría, pero no en la práctica-, $1796-E l$ anuncio de la conclusión inminente de un tratado de paz perpetua en filosofia-, 1797 -Sobre un pretendido derecho de mentir por humanidad-, además de la Crítica de la razón práctica (1788) y sus obras La religión dentro de los límites de la nueva razón (1793), la primera parte de là Metafísica de las costumbres (La doctrina del derecho, 1796), y El conflicto de las facultades (1798). La enumeración es, desde luego, tediosa, pero, en mi opinión, inexcusable, porque pone en guardia frente a lecturas apresuradas de lo que, desde luego, es el texto kantiano más conocido sobre el particular, pero no el único y, sobre todo, no ajeno al sistema de Kant, si se permite la expresión.

Los supuestos básicos que, en mi opinión, deben ser tenidos en cuenta, son los siguientes:

En primer lugar, como señala Weil, ${ }^{1}$ la conocida definición del hombre como ser "razonable y finito", ${ }^{2}$ es decir, a la vez sujeto, de-

1 Cfr. Weil, E., “Kant et le problème de la politique” en La Philosophie politique de Kant, Institut International de Philosophie Politique, Annales de philosophie politique, 4, París, PUF, 1962, Pp. 4 y ss.

${ }_{2}$ Kritik der Praktische Vernunft, §7, Grundgesetz der reinen praktischen Vernunft; Anmerkung A57, pp. 142-143 de la ed. de Werke, IV. 
terminado por sus instintos y necesidades como si de un mecanismo se tratase, como uno más de los animales sometido a la naturaleza y, a la vez, "capaz de pensar lo que por su constitución y la de su conocimiento es incapaz de conocer" ${ }^{3}$ Por eso puede escribir: "con una madera tan retorcida como es el hombre no se puede conseguir nada completamente derechon ${ }^{\text {4 }}$ (aunque por otra parte, como veremos, dé gracias a la naturaleza por la ungesselige Geselligkeit humana), de forma tal que, en realidad, la historia de la libertad comienza con el mal en cuanto es obra del hombre, mientras que la de la naturaleza con el bien, como obra que es de Dios. ${ }^{5}$ Precisamente porque es libre y abusa de su libertad, el hombre, es "un animal que, cuando vive entre sus congéneres, necesita de un señor [...] que le quebrante su propia voluntad y le obligue a obedecer una voluntad valedera para todos, para que cada cual sea libre". ${ }^{6}$ El problema es cómo encontrar ese jefe, y cómo conciliar con eso la libertad. La respuesta de Kant, como apunta González Vicén, ${ }^{7}$

3 Como es sabido, el núcleo de la especificidad de la razón práctica puede ser formulado precisamente asf, afirmando que la necesidad de obrar excede siempre en el hombre a su posibilidad de conocer. Justo con respecto a la distinción entre conocer y pensar sobre la que llama la atención Weil, advierte Kant en el prólogo de la segunda edición de la Kritik der Reinen Vernunft (B XXVI y nota k), “todo posible conocimiento especulativo de ia razón se halla limitado a los simples objetos de la experiencia. No obstante, hay que dejar siempre a salvo [...] que, aunque no podemos conocer esos objetos como cosas en á mismas, sí ha de sernos posible, al menos, pensarlos". Y añade en la nota $k$ : "el conocimiento de un objeto implica el poder demostrar su posibilidad [...] Puedo, en cambio, pensar lo que quiera, siempre que no me contradiga [...] aunque no pueda responder de si, en el conjunto de todas las posibilidades, le corresponde o no un objeto. Para conferir validez objetiva (posibilidad real, pues la anterior era simplemente lógica) a este concepto, se requiere algo más. Ahora bien, este algo más no tenemos por qué buscarlo precisamente en las fuentes del conocimiento teórico. Puede hallarse igualmente en las fuentes del conocimiento práctico" (citamos la trad. de P. Ribas en Alfaguara, Madrid, 1978, p. 25). Véase, con más detalle, el epígrafe 22 ("la categoría no tiene otro uso para el conocimiento de las cosas que su aplicación a objetos de experiencia") de la sección segunda (Deducción de los conceptos puros del entendimiento) del capitulo II del Libro primero (Analítica de los conceptos) de la analítica trascendental. Sobre la limitación del conocimiento de los propios motivos, véase Metaphysik der Sitten, Tugendstheorie, Einl. VIII, 1.

4 Idee zu einer allgemeinen Geschichte in weltbuirgerlicher Absicht, 60. princ. (hay trad. cast. de E. Imaz, FCE, México, 1978; la cita en la p. 51), Werke, VI, p. 41 .

Mutmaßlicher Anfang der Menschengeschichte (hay trad. cast. en el libro mencionado en la nota anterior; la referencia, en las pp. 78-79), Werke, VI, p. 93.

6 Idee, 6o. princ. (cita en la p. 50), Werke, VI, p. 40.

7 De Kant a Marx. Estudios de historia de las ideas, F. Torres, Valencia, 1984, pp. 83-85. 
será la noción formal del Estado como condición posible del derecho, el Estado como idea necesaria en el ámbito de la razón práctica -rompiendo con la tradición política que negaba todo valor propio al Estado-, con justificación absoluta, deducida de la razón a priori: no se asienta en el bienestar o la felicidad del hombre, sino que tiene un fin en sí, tiene "objetividad práctica" y por eso no se puede quererlo o no. ${ }^{8}$ Todo ello, finalmente, desde el convencimiento - la confianza, porque así lo confiesa Kant: ich vertraue - ${ }^{9}$ en el progreso en la historia como consecuencia de la Ilustración, que es un proceso recién desencadenado, no acabado ${ }^{10}$ ("¿es que vivimos en una época ilustrada?"; la respuesta será: no, pero sí en una "época de Ilustración"), cuyo motor es aparentemente una minucia: "Para esta ilustración no se requiere más que una cosa, libertad; y la más inocente entre todas las que llevan ese nombre, a saber: libertad de hacer uso público de su razón íntegramente". ${ }^{11}$

Pues bien, en la Crítica de la razón pura, donde encontramos expuesto el proyecto kantiano (la crítica), se hace mención de la necesidad de una discusión pública y libre. El primer texto es, posiblemente, el prólogo de la primera edición, cuando al hilo de la discusión sobre la decadencia de la metafísica, ilustrada por los versos de Ovidio, se propone el Tribunal de la crítica de la razón pura. En nota a pie de página escribe Kant: "Nuestra época es, de modo especial, la de la crítica. Todo ha de someterse a ella. Pero la religión y la legislación pretenden de ordinario escapar a la misma. La primera a causa de su santidad y la segunda a causa de su majestad. Sin embargo, al hacerlo, despiertan contra sí mismas sospechas justificadas y no pueden exigir un respeto sincero, respeto que la razón sólo concede a lo que es capaz de resistir un examen público y libre”. ${ }^{12}$ En realidad, como se conviene en reconocer, toda la filosofía práctica de Kant se apoya sobre esa tesis, sobre

8 En el mismo sentido que González Vicén, Bobbio, en N. Bobbio y M. Bovero, Sacietá e Stato nella filooofia política moderna, Il saggiatore, Milano, 1979, pp. 114 y ss., reitera la oposición frontal de Kant al Estado Paternalista -necesariamente despótico-, eudemónico, lo que, como se verá, es de la mayor importancia para el tema que nos ocupa y que desarrollaré con detenimiento.

- Über der Gemeinopruch das mag in der Theorie richtig sein, taugt ater nicht für die Praxie, Werke, III, p. 172.

10 War ist Arfklärung?, Werke, VI, p. 59. (Hay traducción castellana en la colección de varios de sus escritos menores titulada Filosofia de la historia (Trad. E. Imaz), FCE, México, 1978; la cita en p. 34.) En el mismo sentido, H. Béjar, en su artículo "Kant: espacio político y publicidad", Sistema, 59, 1984, p. 118.

11 Ibid., Werke, VI, p. 55 (en la trad., p. 28).

12 Kritik der reinen Vernunft, A XI, nota k. (cit. ed. Alfaguara, p. 9). El subrayado final es mio. 
la afirmación de que la razón es comunicación, y que se basa en la libertad de crítica. Todo ello se manifiesta con absoluta nitidez en la Doctrina trascendental del método, cuando, al estudiar en el capítulo primero La disciplina de la razón pura, se plantea, en su sección segunda, lo que Kant titula uso polémico. Esas páginas de la sección segunda son, a mi entender, capitales para la comprensión de la postura de Kant, que, como resumiera Fichte, no es sino el intento de construir la república sobre los pilares de la libertad de pensamiento y la noción de comunidad. No olvidemos que, como el propio Kant sostendrá más adelante, esa república pura es die einzige rechtsmässige Verfassung. ${ }^{13}$ Pues bien, es allí donde Kant afirma solemnemente que la razón pura, que debe someterse siempre a la crítica, "no puede oponerse a la libertad de esa crítica sin perjudicarse y sin despertar una sospecha que le es desfavorable [...] Sobre tal libertad se basa la existencia misma de la razón, la cual carece de autoridad dictatorial. Su dictado no es nunca sino el consenso de ciudadanos libres, cada uno de los cuales tiene que poder expresar sin temor sus objeciones e incluso su veto". ${ }^{14}$ Retengamos ahora la expresión Einstimmung der freier Bürger, que será de la mayor importancia a la hora de fijar los límites (la crítica) de las tesis de Kant. Es claro, por otra parte, que la posición de Kant es el corazón de la Aufklärung, la negación del dogmatismo (el que nadie pueda contestar con validez apodíctica la corrección de una proposición), desde el convencimiento de que "el litigio favorece a la razón", que es preciso combatir al adversario "únicamente con armas de razón". Por eso el rechazo - que Kant pone en boca de Hume- de "toda coerción que se pretenda ejercer sobre la razón". Hay que tener en cuenta que Kant escribe teniendo en mente la figura de Federico el Grande y las dificultades que encuentra la libertad de expresión (recuérdese la reprensión de que será objeto por Wollner, el ministro de Federico II, que sucede al gran monarca ilustrado a la muerte de éste en 1786). Por eso, se ve en la necesidad de negar que esa libre crítica amenace el bien público, primero acudiendo al expediente académico (en realidad estos litigios de la razón son ajenos por completo a los problemas de la comunidad), pero pronto al corazón del argumento: “A la razón le hace mucha falta esa lucha. Ojalá se hubiese desarrollado antes y con ilimitada y pública autorización" (el subrayado es mío), por dos considera-

18 Rechlalehre, ep. LII (la cita; en la trad. cit., p. 157), Werke, IV, p. 464.

14 Kritik der reinen Vernunft, A 738-739/B 766-767 (en la trad. cit., p. 590). En lo que sigue, las citas textuales están tomadas de los parágrafos de esa sección segunda: A 739-740/B 767-768, A 744-745/B 772-773, A 747/B 775 (y las pp. 592-595 de la ed. cit.) 
ciones de la mayor importancia respecto al problema que tenemos planteado: ${ }^{15}$

a) En primer lugar, porque "no hay nada más perjudicial" -y no sólo para el conocimiento sino para toda buena causa- "que la perfidia, el disimulo y el engaño";

b) Además, porque "exponer a pública consideración los propios pensamientos y las dudas que no es capaz de resolver uno mismo" no es grave quebranto de la sociedad y el orden, sino, muy al contrario, "entra ya en el derecho originario de la razón humana, la cual no reconoce más juez que la misma razón humana común, donde todos tienen voz".

Lo que tenemos aquí enunciado es la exigencia de una discusión abierta, pública y libre, en la que todos deben participar (aunque ese todos sufra importantes restricciones, como veremos), desde el postulado de la libertad de expresión/comunicación, que excluye el principio de autoridad, el dogmatismo y el secreto. Son ésos los temas que Kant irá desarrollando hasta la formulación del principio de publicidad, pues, como advierte Jaspers, ${ }^{16}$ la comunicabilidad y la comunicación sin restricciones son la esencia de la razón.

Efectivamente, en los dos escritos de 1784 - Was ist Aufklärung? y las Ideen - se avanza en el significado de la libertad de crítica, en su justificación y en su alcance político, desde la convicción casi angustiosa de que la libertad de expresión corre peligro ante la desaparición inminente de su gran protector, el rey ilustrado. El primero de esos escritos (como tantos otros de Kant, aparecido en la Berlinische Monatsschrift) es el texto básico para comprender la Aufklärung como movimiento intelectual y político, pero, además, en él encontramos algunas de las claves de lo que tratamos de esclarecer: en efecto, se trata de la línea argumental que podía resumirse de la siguiente forma: el público puede llegar a ilustrarse siempre que se conceda la libertad de hacer uso público de su razón ("el uso que en calidad de maestro se puede hacer de la propia razón ante el gran público del mundo de lectores") en la medida en que se es "miembro de un ser común total y hasta de la sociedad cosmopolita de los hombres, por lo tanto en calidad de maestro que se dirige a su público por escrito haciendo uso de su razón, puede razonar sin que por ello padezcan los negocios en los que le corresponde, en parte,

15 Kritik der reinen Vernunft, A 749/B 777 (pp. 596-597) y A 752/B 780 (p. 598). 16 K. Jaspers, Los grandes filósofos, (II) (trad. cast. de P. Simón, Sur, Buenos Aires, 1968), p. 390. 
la consideración de miembro pasivo" 17 El ciudadano-pero, no lo olvidemos, no todos los hombres - tiene pues el derecho de la libre crítica en cuanto a su pertenencia a la comunidad de hombres (de ahí la restricción de lo que Kant llama uso privado), y esa libertad es, según el propio Kant, "ilimitada" e irrenunciable: "la simple y pura renuncia aunque sea por su propia persona, y no digamos por la posteridad, significa tanto como violar y pisotear los sagrados derechos del hombre", y un acuerdo - confirmado por el soberano, por el congreso o por pacto internacional- en eśe sentido, debe ser calificado como "crimen contra la naturaleza humana". ${ }^{18}$ En el orden político, la consecuencia es la afirmación de la libertad de conciencia - la emancipación de la tutela religiosa-, la libertad de crítica respecto a la legislación ${ }^{19}$ y el principio de legitimidad: "Toda autoridad legislativa descansa precisamente en que asume la voluntad entera del pueblo en la suya propia", porque "la piedra de toque de todo lo que puede decidirse como ley para un pueblo se halla en esta interrogación: ¿es que un pueblo hubiera podido imponerse a sí mismo esta ley?" 20 Tal principio de legitimidad en el que el consenso juega un papel diverso que en Rousseau, será desarrollado en obras posteriores y lo comentaré más adelante. Lo que ahora importa es que, ante semejante afirmación, y para hacer frente a la objeción obvia (¿acaso no se está introduciendo un principio de anarquáa?), Kant responde, por así decirlo, en dos planos:

a) En primer lugar, afirma que no hay ningún peligro para la seguridad, para la "tranquilidad pública y la unidad del ser común", y aduce la propia experiencia de Federico el Grande;

b) pero, en segundo lugar, se recurre inmediatamente a la constatación de que no se ha alcanzado la Ilustración, sino que se está en el comienzo de un proceso y, por consiguiente, aún no puede ser remplazada la autoridad del gobernante por la del pensamiento.

17 Was ist Aufkärung?, Werke, VI, pp. 55-56 (ed. cast. cit. de FCE, pp. 28 y 29).

18 Ibid., p. 58 (ed. cast. cit., pp. 32 y 33). De ahí el carácter fundamental que tiene para la legitimidad política el principio de libertad crítica. En ese sentido, en mi opinión, las conocidas tesis dé Ellas Dlaz (véase su De la maldad estatal y la coberanía popular, Debate, Madrid, 1986, pp. 59 y ss.), encontrarian apoyo en esos textos de Kant.

19 lbid., p. 60 (ed. cast., pp. 35-36).

20 Ibid., pp. 58-59 (ed. cast., pp. 33 y 32). Ese criterio de Rechtsmäsrigkeit es el que vuelve a enunciar en Über den Gemeinspruch, en el corolario de la 2a. sección (contra Hobbes). 
En ese sentido es que se aduce que la obediencia está gàrantizada por el ejército y la administración, que actúan auxiliando la tarea de la $A$ ufḱlärung, la tarea de los filósofos, tal y como expondrá detalladamente en Zum ewigen Frieden y en Der Streit der Fakultäten. Por eso la conclusión es el deber de obediencia, el irazonad todo lo que queráis y sobre lo que queráis, pero obedeced!, que luego encontrará una expresión más rotunda en la afirmación del carácter incondicionado del deber de obediencia como primer deber del ciudadano. ${ }^{21}$

Esas tesis encuentran su expresión en el artículo en el que Kant expone su idea de una historia universal en sentido cosmopolita, al exponer el plan secreto de die grosse Künstlerin, la naturaleza: efectivamente, es ahí donde se justifica la necesidad de someter la libertad del hombre al "poder irresistible" de la constitución civil perfectamente justa, lo que es enunciado en el V principio: "El problema mayor del género humano, a cuya solución le constriñe la naturaleza, consiste en llegar a una sociedad civil que administre el derecho general", el problema que "más tardíamente resolverá la especie humana" y que conducirá a la "asociación ciudadana completa de la especie humana" ${ }^{22}$ El modelo antropológico que sirve de referencia, la ungesellige Geselligkeit con la que la naturaleza ha marcado al hombre, tiene una importancia decisiva para comprender los límites de la construcción kantiana, pues, como veremos y de acuerdo con la interpretación, p. ej. de González Vicén y Bobbio, lo que se traduce aquí es el modelo liberal, coherente con los postulados de la escuela escocesa de economía política, y que se resuelve en la primacía del mercado y sus libertades como finalidad básica del Estado, de modo que, en realidad, la asociación ciudadana es asociación de quien compite libremente, del burgués. La necesidad de la coacción aparece así evidente, como la imposibilidad de que la voluntad particular se convierta en criterio de justicia, en ley.

Las consecuencias jurídico-políticas más directas de lo que acabo de recoger se encuentran en tres escritos posteriores: $\ddot{U b e r}$ den $\mathrm{Ge}$ meinspruch, Zum ewigen Frieden y en la Rechtslehre. Sin embargo, antes conviene detenerse en otro de los artículos publicados por Kant en la Berlinische Monatschrift, y en concreto, en el que aparece en octubre de 1786 con el título Was heisst: sich im Denken

21 En el mencionado corolario de la 2a. sección de Über den Gemeinspruch, Werke, VI, p. 154 y en la Observación General A del epigrafe XLIX de la Rechtslehre, Werke, IV, p. 438. El texto, por supuesto, está en War ist Aufklörung?, Werke, VI, p. 55.

22 Idee, Werke, VI, pp. 39-40 y 47 (ed. cast. de FCE, V, VI y IX, pp. 48, 50 y 61). Como es evidente, se trata de un preludio de lo que desarrollará en Zum ewigen Frieden. 
orientieren?, y que ha sido calificado ${ }^{23}$ como uno de los textos de encrucijada de Kant no sólo porque se encuadra en lo que se denomina Pantheismusstreit, el debate en el que el "estigma" de Spinoza aletea sobre la Ilustración alemana (ni por el rechazo de la Schwarmerei), sino sobre todo porque es la decisiva toma de posición sobre una libertad que la muerte cercana de Federico hace incierta. El leitmotiv, que nos afecta decisivamente, es la vinculación entre razón y libertad: si nos podemos orientar en el pensamiento es por el principio del sentimiento de Das Bedürfniss der Vernunft, ${ }^{24}$ necesidad que se puede considerar bajo el aspecto teórico, pero también, lo que es weit wichtiger, en su uso práctico, en la prescripción de leyes morales, que conducen al "mayor bien posible en este mundo: la moralidad, que no es posible más que por la libertad". ${ }^{25}$ Pues bien, es en ese contexto donde se plantea el problema de la libertad de pensamiento, de su contenido y límites: a la libertad de pensamiento se oponen la coacción civil, la coacción sobre la conciencia y la tutela de la razón. Es al examinar la relación entre libertad de pensamiento y coacción civil cuando Kant muestra que la libertad, "el único tesoro", "el único que puede aportar un remedio", es inseparable de la libertad de expresión y comunicación, porque no hay libertad de pensamiento, "no pensaríamos mucho ni bien si no pensáramos en común con los demás" ${ }^{26}$ Esa es la raíz de toda libertad, esa es la tarea de la Aufklärung - una tarea lang-wierig-, porque "la razón humana no deja jamás de tender hacia la libertad". ${ }^{27}$ Esa libertad de pensar que se asienta en la exigencia de pensar por sí mismo, consiste en "buscar la piedra de toque de la verdad en la razón propia [...] plantear esta exigencia respecto a todo lo que se deba admitir" ${ }^{28}$ Si se pierde esta libertad, en lugar de la comunidad ciudadana surgirá la Babel, y en lugar del respeto, la interpelación del superior al súbdito.

Coherentemente con esto, Kant rechaza de modo tajante la conocida argumentación de la negación de la libertad por falta de madurez, que está en la base de todo poder absolutista, del modelo de Estado paternalista y despótico, bien que solamente afecta ese

23 Asl Alquié, en el prefacio a la ed. francesa en Vrin, París, 1978, "un lexte de grande importance philorophigue et historique" . Para Cassirer, este artículo es muy característico del modo de pensar de Kant (cfr. su introducción a la edición de las Werke de Kant).

24 En Was heiout: rich im Denken orientieren?, Werke, III, p. 270.

25 Ibid., p. 274.

26 Ibid., p. 280 . Como se verá, Fichte hereda casi al pie de la letra esa tesis central.

27 Ibid., p. 282.

28 Ibid., nota a p. 283. 
rechazo a la libertad de religión: "Confieso que no llego a acomodarme a la expresión [...] tal pueblo (que está a punto de elaborar una libertad bajo leyes) no está maduro para la libertad, los siervos de un propietario no están aún maduros para la libertad e, incluso, los hombres en general no están aún maduros para la libertad religiosa. Según tal presupuesto, la libertad no llegará nunca, porque no se puede madurar a la libertad si antes no se ha puesto en libertad (hay que ser libre para saberse servir de sus fuerzas según fines razonables), las primeras tentativas serán ciertamente rudas. .. "29 Por eso, puede reafirmar el principio de legitimidad que veíamos adelantado en Was ist Aufklärung? Basándose en la libertad como principio y fin, se postula la soberanía del pueblo: la coincidencia pública es lo que permite hablar de leyes públicas, ${ }^{30}$ pues el principio de soberanía del pueblo sólo puede ser realizado bajo el presupuesto de un uso público de la razón. ${ }^{31}$ Efectivamente, cuando Kant se plantea la relación de la teoría y la práctica en el derecho político (que, significativamente, subtitula "Contra Hobbes"), comienza delimitando la noción de derecho, y la relación entre libertad y coacción. El texto es importante: "El concepto de un derecho exterior en general se desprende enteramente del concepto de la libertad en las relaciones exteriores de los hombres entre sí, y no tiene absolutamente nada que ver con el fin ni con la prescripción de los medios [...] El derecho es la limitación de la libertad de cada uno a condición de su acuerdo con la libertad de todos en tanto éste es posible según una ley universal; y el derecho público es el conjunto de leyes externas que hacen posible tal acuerdo universal. Luego, si toda limitación de la libertad por el arbitrio de otro se denomina coacción, resulta de ello que la constitución civil es una relación de hombres libres que (sin perjuicio de su libertad en el todo de su unión con otros) están sometidos a leyes de la razón. Es que la razón lo quiere así, y ciertamente, die reine a priori gesetzgebende Vernunft". ${ }^{32}$ Esto planteará indudablemente problemas tan graves como el de conciliar el poder incondicionado de obediencia con la libertad, o la función real del consenso, que abordaré en seguida.

29 Religion innerhalb der Grenzen der Bloßen Vernunft, IV, 2 Teil, 4, n. 3, Werke, IV, pp. 862-863.

En ese sentido, Habermas, Historio y crítica de la opinión pública (traducción de A. Domenech de Strukturwandel der Öffentlichkeit. Untersuchungen zu einer Kategorie des bürgerlichen Gesellachaft), Barcelona, Gili, 1981, p. 140.

31 Über den Gemeinopruch, II, Folgerung, Werke, VI, p. 153.

32 lbid., II, p. 145. En el mismo sentido, Rechtslehre, esp. XLIX, Werke, IV, pp. 435-436. En Der Streit der Fakultälen, sec. 2, art. 6, nota 1, Werke, VI, p. 359 , repetirá la idea de que la soberanía del pueblo se basa en la libertad como principio y fin. 
Ahora interesa avanzar algo más sobre las consecuencias que Kant extrae de lo anterior.

Precisamente esa característica del derecho - límite de la libertad en una ley universal de libertad- permite que Kant afirme: "Die Natur unwiderstehlich dass das Recht zuletzt die Obergewalt eqhalte" ${ }^{33}$ Ese Estado sometido al derecho tiene como presupuestos los tres conocidos principios a priori de la condición civil (la libertad en cuanto hombre, la igualdad en tanto que súbdito, la independencia como ciudadano). ${ }^{34} \mathrm{La}$ sociedad asentada sobre esos principios es un fin en sí que cada uno debe proponerse, de conformidad con la naturaleza racional del hombre. Por eso no hay voluntad particular capaz de dar leyes justas al Estado, sino el acuerdo de voluntades. Ahora bien, ¿cuál es el sentido de ese contrato, de ese consenso? La respuesta de Kant es que se trata de una simple idea de la razón, que, como indica González Vicén, ${ }^{35}$ sirve para hacer comprensible el concepto de voluntad unida como presupuesto de derecho público, la noción formal del Estado como condición de posibilidad del derecho. En otras palabras, como ha escrito Weil, ${ }^{36}$ lo que subyace al principio de legitimidad enunciado en $\ddot{b}$ er den Gemeinspruch bajo la modalidad als ob, "dictar sus leyes como si pudieran haber emanado de la voluntad colectiva de todo un pueblo y considerar a todo súbdito, en tanto que quiere ser ciudadano, como si hubiera concurrido a formar con su sufragio una voluntad de ese tipo [...] si es posible (únicamente con eso) que un pueblo diera su asentimiento a una ley, es un deber tenerla como justa" ${ }^{37}$ lo que subyace, advierte Weil, es que el pueblo "debe poder querer obedecer como primera exigencia de la moral", lo que, volviendo al análisis de González Vicén, significa que la función de la especulación política en Kant no es "regulativa" (no trata de fundamentar el nexo entre el Estado y unos fines), sino "constitutiva". 38 Las consecuencias son muy importantes: el poder soberano es incondicionado, y toda oposición es "el crimen más grave y condenable", el pueblo no tiene otra cosa que hacer más que obedecer, precisamente en virtud de la máxima salus publica suprema civitatis lex est, porqué esa salus publica es "la constitución legal que garantiza la libertad de cada uno mediante

33 Über den Gemeinopruch, pp. 171-172. Zum ewigen Frieden, art. 1, Werke, p. 225.

34 Ibid., II, p. 145. Igualmente, Rechtslehre, ep. XLVI, p. 433 y Zum ewigen Frieder, art. 1, nota 1 y Zusatz, p. 204 y nota.

\$5 Cfr. op. cit. en nota 8, pp. 80 y ss. Cfr. igualmente Eatudios de hiotoria de la filosofía, Debate, Madrid, 1985, p. 119.

36 Op. cit., p. 43.

37 Über den Gemeinspruch, pp. 153-154.

38 Op. cit., p. 81. 
las leyes": si una ley pública es conforme al derecho, el derecho de coacción "es tal que no se puede oponer a él (es irresistible)". ${ }^{39} \mathrm{En}$ la Rechtslehre será aún más contundente: el poder limitado es un sinsentido, no se debe disputar sobre la existencia del pactum subjectionis como sobre un ius controversum, "el soberano en la ciudad no tiene hacia el súbdito más que derechos, no deberes", y aún con más claridad: "no puede haber ningún artículo en la constitución que conceda a un poder en el Estado el derecho de oponerse al soberano en caso de que éste violase la constitución [...] no hay, pues, contra el poder legislativo, soberano de la ciudad, ninguna resistencia legítima de parte del pueblo, porque un estado jurídico no es posible más que por la sumisión a la voluntad universal legislativa: ningún Rechts des Aufstandes (reditio), ni tampoco des Aufruhrs (rebellio) $[. .$.$] ni Vergreifung an seiner Person, j a$ an seinen Leben (monarchomachismus sub specie tyrannicidii)" ${ }^{40}$ Pues bien, es al hilo de estas consideraciones cuando aparece aducido el principio de publicidad -tanto en Über den Gemeinspruch como en la Rechtslehre- y por eso resulta necesario detenerse en el análisis de esos textos que no sólo resultan de primordial interés para nuestro tema, sino también a los efectos de resolución de una de las aparentes contradicciones que han preocupado a todos los estudiosos de Kant y a la que nos referíamos más arriba: ¿cómo conciliar el rechazo absoluto del derecho de resistencia y su construcción del derecho como garantía de libertad, amén de su actitud personal ante los movimientos sociales y políticos que hoy llamaríamos de liberación, como las revoluciones americana y francesa?

Ante todo, la presentación del principio de publicidad. En $\ddot{U} b e r$ den Gemeinspruch, se arranca de la discusión acerca del pretendido derecho de resistencia del pueblo, un derecho de coacción contra él: esto le parece a Kant una "contradicción evidente" (ein klarer Widerspruch), porque sería necesario que la constitución existente contuviera igualmente un poder opuesto públicamente constituido, otro jefe de Estado que velara por los derechos del pueblo... sería preciso, pues, que la "constitución autorizase la rebelión, que se proclamara públicamente el derecho y la manera de usar de ella". ${ }^{41}$ En Zum ewigen Frieden, este argumento es expresamente reiterado al exponer en el Apéndice III el concepto trascendental de derecho público que es el principio de publicidad, precisamente como ejemplo de su virtualidad para resolver problemas y, en concreto, en el ámbito del derecho político/derecho interno, ius civitatis, respecto

39 Über den Gemeinopruch, Folgerung, pp. 154-155.

40 Rechislehre, Allgemeine Anmerkung A, Werke, IV, p. 439.

11 Über den Gemeinspruch, Werke, VI, p. 160 y nota. 
al problema "que muchos consideran de difícil solución" acerca de la legitimidad de la revolución: "la injusticia de la rebelión se pone de manifiesto, por tanto, en que si se expresaran públicamente sus principios, no se podrían realizar sus propósitos. Habría que mantenerlos en secreto necesariamente". Si, por el contrario, abiertamente se incluyera (como fue el caso en los artículos 2 de la Declaración francesa de 1791 y 35 de la de 1793 , lo que no recoge Kant, y como es el caso hoy de la Ley fundamental de Bonn, arts. 20-24) se trataría de una contradicción entre dos pretendidos soberanos, lo que conduciría a la imposibilidad de la instauración del Estado. ${ }^{\mathbf{4 2}}$ Lo único que se admite es la resistencia negativa del pueblo en el parlamento, una resistencia al ejecutivo, no al legislativo.

¿Qué le queda, en ese caso, al pueblo? Además de esa "resistencia negativa", lo que resta es lo que Kant califica como das einzige Palladium des Volksrechte, la libertad de escribir, y ahora se retoman las ideas de Was ist Aufklärung?: "la humanidad presenta una vocación natural a comunicarse mutuamente sobre todo aquello que afecta al hombre en general"; es preciso una "obediencia en espíritu de libertad" y ello sólo se consigue si cada uno tiene el derecho a ser convencido en espíritu de liberdad y mediante la razón, de que la coacción es conforme al derecho. Por esa razón formula lo que sería el principio general según el cual el pueblo debe juzgar negativamente sobre su derecho: "lo que un pueblo no puede decidir por sí mismo, el legislador tampoco puede decidirlo respecto al pueblo". ${ }^{43}$ En esta tarea de argumentación racional de la obediencia será decisivo el papel de los filósofos, presentados ahora como publicistas: efectivamente, en el segundo suplemento de la Paz perpetua ("Un artículo secreto para la paz perpetua"), se afirma textualmente: "El Estado requerirá, por tanto, a los filósofos en silencio (haciendo de ello un secreto), lo que significará tanto como que les dejará hablar libre y públicamente sobre los principios generales de la guerra

\section{2}

Zum ewigen Frieden, Anhang II, Werke, VI, pp. 245-246 (en la trad. cast. cit., pp. 62-63). Por su parte, en la Rechtolehre, al afirmar ese deber del pueblo de soportar el abuso, se reitera que la sublevación es contraria a la ley y subversiva para toda constitución legal: "Para que la sublevación fuese permitida, sería menester que hubiese una ley pública que la autorizase” lo que supondría la contradicción de que el pueblo fuese al tiempo súbdito y soberano, y que la legislación suprema se postulara a sí misma como no suprema, amén de conducirnos a la cuestión del árbitro en ese irresoluble conflicto (Werke, IV, p. 440).

43 Über den Gemeinspruch, Werke, VI, pp. 162-163. La formulación literal, en la que continúa el método del als ob, es la siguiente: "Was ein Volk über vich selbat nicht berchließen Kann, das Kann der Gesetzgeber auch nicht über dae Volk beschließen". 
y del establecimiento de la paz", ${ }^{44}$ lejos, por supuesto, de la concepción del filósofo-rey o del rey-filósofo: aquí de lo que se trata es del filósofo publicista, al que es preciso que todos (el público, el jurista y el soberano) oigan, hasta el punto de que es tarea del rey impedir que desaparezcan los filósofos o queden reducidos al silencio, imperativo este que, por desgracia, parece haber quedado en desuso. Es evidente que nos encontramos aquí ante la cara oculta $o$, si se quiere, menos patente, de la exigencia de la publicidad, de la comunicación libre y pública. En mi opinión, junto a lo que Kant expresamente presenta como principio de publicidad (del derecho público), esta otra exigencia, ligada directamente a la libertad de expresión y comunicación, constituye un elemento básico de lo que hoy podría ser aducido como principio de publicidad en conexión, como veremos, con la transformación de la libertad de expresión en derecho a la información. En parte lo advierte Kant cuando subraya que la libertad de pluma y comunicación constituye, por lo demás, un requisito imprescindible para que el soberano, el gobierno, esté informado de lo que constituye auténticamente la voluntad del pueblo y no incurra así en contradicción. ${ }^{45}$ Desde luego se trata del sentido descendente (no del ascendente), que es el que conjuga con la democracia.

Pero, junto a esa dimensión del principio de publicidad, hemos visto que Kant ofrece en la Paz perpetua un análisis detallado de lo que pasa por ser "el" principio kantiano de publicidad, y en el que resulta ahora necesario detenerse. Lo interesante del principio, en mi opinión, no es tanto su formulación: como se recordará, en realidad son dos las fórmulas trascendentales del derecho público: "son injustas todas las acciones que se refieren al derecho de otros hombres cuyos principios no soportan ser publicados" y, en segundo lugar, tras constatar que tal principio entra en conflicto con las exigencias de la política en el derecho de gentes ${ }^{46}$ - las tres antinomias entre política y moral, entre la política y la moral como

44 Zum ewigen Frieden, Werke, VI, p. 228 (de la trad. cast., p. 42). Se trata, desde luego, del uso público de la razón que debe hacer todo el mundo, como velamos que proclamaba Kant en Was ist Aufklärung? En el mismo sentido, véase Der Streit der Fakultäten, II, secc. 8, p. 363.

15 Über den Gemeinspruch, Pp. 162-163. Es evidente, por lo demás, la confianza en la virtualidad política del principio de libre critica y de su consecuencia - la libertad de expresion. Aquí, como en otros ámbitos, no deja de advertirse un paralelismo con Spinosa (por ej.: Tractatus Theologicus-Politicus, cap. XX), que mantiene también el principio de libre crítica y obediencia.

46 Al respecto, resulta del mayor interés la consulta, no exenta de dificultad por lo prolijo y casuístico de la exposición, del capítulo titulado De Dolis et mendacio, en el De iure belli ao pacis de H. Grotius, ya citado. 
teoría del derecho (según precisa el propio Kant) - formula un principio "transcendental y positivo" del derecho público: "todas las máximas que necesitan de la publicidad (para no fracasar en sus propósitos) concuerdan con el derecho y la política a la vez" ${ }^{47}$ Lo interesante, sobre todo, es la fundamentación misma, y su significado. Efectivamente, lo que sostiene Kant es que en el derecho público lo básico, lo universal, es la forma misma de la publicidad, que caracteriza todo lo jurídico, porque la justicia sólo puede ser pensada como públicamente manifestada: por eso toda pretensión que se pretenda conforme a derecho debe tener la posibilidad de ser publicada. Se trata pues, y esto es lo que quería destacar - tal y como lo ve penetrantemente Kant- no de una exigencia moral sino de un principio jurídico, bien que "un principio negativo", como por otra parte es lo frecuente, si se piensa en el liberalismo que subyace a la concepción de Kant. La publicidad, tal y como lo manifiesta la segunda formulación, es garantía de la posibilidad de la unión de los fines de todos y, por consiguiente, de la libertad, lo que es tanto como decir del mismo derecho. ${ }^{48}$ Esta tesis queda reforzada en escritos posteriores, cuando se fustiga la mentira, el engaño y el secreto como los más graves perjuicios para la humanidad, porque descalifican la fuente misma del derecho, ${ }^{49}$ así, en su breve artículo Sobre un pretendido derecho de mentir por humanidad (1797) en respuesta a Constant, donde sostiene que la veracidad es un deber que tiene que ser considerado como la base de todos los deberes que se fundan sobre un contrato, deberes cuya ley, si se tolera la menor excepción, sería schwankend und unnütz, ${ }^{50}$ para concluir: respecto a los principios jurídicamente prácticos, no caben excepciones, porque estas negarían la universalidad que es a la que deben la categoría de principios. ${ }^{51}$ Del mismo modo, en la Metafísica de las costumbres (1797) (en la Doctrina de la virtud, 1a. Parte, "Deberes para consigo mismo", Libro I, ep. 9, "Sobre la mentira"), afirma textualmente: "la mentira es el envilecimiento y anonadamiento, por así decirlo, de la dignidad del hombre. Un hombre que no cree él mismo lo que dice a otro tiene menos valor que una simple cosa [...] porque si preten-

17 Zum ewigen Frieden, Anhang II, pp. 245 y 250, (en la trad. cast., pp. 61 y 69).

18 Ibid., pp. 244 y 250-251, (en la trad. cast., pp. 61 y. 69). Obviamente, ello sólo es posible, como se encarga de advertir el propio Kant, cuando se realice el proyecto de federación universal.

49 Über ein vermeintes Recht au: Menschenliebe zu lügen, Werke, IV, p. 638: “Denn vie Schadet jederzeit einen anderen, wenn gleich nicht einem andern Menschen, doch der Menuchheit überhaupt, indem sie die Rechtsquelle unbrauchbar macht".

50 Ibid.

51 Ibid. p. 643. 
diendo comunicar a otro sus pensamientos se usa (de propósito) de palabras que significan lo contrario de lo que se piensa, se propone un fin que va directamente contra el destino natural de la facultad de comunicar sus pensamientos y, por tanto, se abdica de su personalidad: así, el embustero es menos un hombre verdadero que la apariencia engañosa de un hombren ${ }^{52}$ Por fin, y aunque se trata de un escrito anterior a los dos últimos mencionados, pues aparece en 1796, cabe traer aquí el breve e irónico artículo sobre la inminente conclusión de un tratado sobre la paz perpetua en filosofía, que concluye con las siguientes palabras: "si en filosofía tomáramos en serio el mandato: no mentirás, introduciríamos no sólo la paz perpetua en filosofía, sino que la aseguraríamos para todo nuestro porvenir". ${ }^{33}$ De este modo queda patente, en mi opinión, que por principio de publicidad no puede entenderse tan sólo una u otra formulaciones de las enunciadas en la $\mathrm{Paz}$ perpetua, sino también, y sobre todo, la exigencia jurídica de mantener una comunicación libre y racional, de institucionalizar la libertad de expresión y comunicación, de asegurarla y erradicar por tanto el secreto y el engaño en el orden jurídico y político, exigencia perfectamente coherente con el sistema kantiano.

Sin embargo, este proyecto no queda, a su vez, exento de crítica, crítica que se asienta en las limitaciones de los supuestos kantianos, que tienen relación con la respuesta a la interrogante sobre la aparente contradicción de Kant a la que hacíamos mención más arriba: ¿cómo puede ser Kant a la vez defensor de la libertad y rechazar el derecho de resistencia? En mi opinión, hay una primera respuesta, la que proporciona, por ejemplo González Vicén cuando, al hacer notar el cambio que experimentan en Kant las categorías jurídicas del iusnaturalismo, muestra cómo, para el filósofo de Könisberg, lo esencial ya no es la regulación, los fines sustantivos de la convivencia y de su ordenación jurídico-política, sino más bien "su carácter de certeza e inviolabilidad" que "hace del derecho el marco fundamental permanente de la actividad individual y del libre juego de las fuerzas sociales". En otras palabras, para Kant el problema de la resistencia al poder - sigue González Vicén - no es de orden

52 Von der Lüge (Die Metaphyrik der Sitten), Werke, IV, pp. 562-563. En el mismo lugar afirma: "Die Grüßte Verletzung der Pflicht des Menschen gegen sich selbot,"bloß als moralisches Wesen betrachtet (die Menschheit in seiner person), ist das Wideropiel der Wahrhaftdigkeit: die Lüge (aliud lingua promptum, aliud pectore incluoum genere)".

53 Verkündigung des Nahen Abschlusses eiries Traktats zum ewigen Frieden in der Philosophie, Werke, III, p. 416. El texto original, que he traducido un tanto libremente, dice: "Dos Gebot: du sollst (und wenn es auch in der frömmsten Abricht wäre) nicht lügen, zum Grundsatz in die Philosophie als eine Weisheitslehre innigst aufgenommen, würde allein den ewigen Frieden in ihr nicht nur bevirken, sondern auch in alle Zukunft sichern können". 
ético-jurídico, sino, como hemos visto con toda claridad, estrictamente lógico, ${ }^{54}$ porque al partir del presupuesto de la existencia dè un orden cierto e inviolable de la vida en sociedad, garantizado por el soberano, no cabe negarle como soberano. González Vicén concluye así negando que Kant se alinee pura y simplemente con el absolutismo, sino más bien con la "omnipotencia impersonal de la ley o del derecho, necesaria para la idea misma del Estado" y aduce una interesante observación póstuma, contenida en las Lose Blätter en la que se define la libertad civil en términos que' resuenan a Montesquieu. ${ }^{55} \mathrm{Hay}$, con todo, otra vía posible para comprender el problema, vía que pasa por el-análisis de los presupuestos ideológicos que subyacen en la construcción de Kant, y es la vía en la que ha profundizado por ejemplo Habermas. ${ }^{56}$ En la interpretación de este autor, los textos mencionados de Kant (y sobre todo lo que he propuesto más arriba como los supuestos previos, centrados en páginas de la Crítica de la razón pura, en la Crítica de la razón práctica y en las Ideas), como ha hecho notar entre nosostros Ballesteros, ${ }^{57}$ serían "una variación del tema de Mandeville: private vices, public benefits", desarrollando los presupuestos sociológicos de la publicidad políticamente activa, vinculados a la autonomía privada que es posible por las relaciones entre poseedores de mercancías en libre competencia. ${ }^{58}$ Como es sabido, la autonomía arraiga en la esfera del tráfico mercantil: es el texto clave de Über den Gemeinspruch: "quien tiene derecho a voto en esta legislación se llama citoyen, es decir, Staatsbürger, y no Stadtbürger, bourgeois. La única cualidad que es necesaria para ello, aparte de la natural (no ser niño, no ser mujer) es ser su propio amo (sui iuris), por tanto, poseer alguna propiedad (para lo que puede contarse obra de arte, artesanía, o talento físico o científico) que le permita proveer a su sostén [...] es decir que no lo gane sino por alienación (Veraüsserung) de lo que le es propio y no consintiendo que otros exploten sus fuerzas" (en nota al pie distinguirá entre praestatio operae y alienación, entre operarii y artf́fices: sólo quien entrega su opus, su propiedad y no su opera, puede ser ciudadano). ${ }^{59}$ La consecuencia obvia es que sólo los propietarios son el público raciocinante. Como ha

56 p. cit., pp. 95-97.

$O p$. cit., Pp. 146 y 88 .

Así, en su trabajo sobre el artículo 1.1 de la Constitución española de 1978, incluido en el colectivo de la U. de Valencia, La Constitución española de 1978 (Valencia, 1981), pp. 37-44.

58 Op. cil., p. 142.

59 Über den Gemeinopruch, pp. 148-149. 
visto penetrantemente Habermas, Kant actúa aquí de acuerdo con la solución de la tercera antinomia de la razón pura: todo efecto tiene que ser pensado como libre en relación con su causa inteligible, y como necesario, en relación con su manifestación empírica: así intenta conciliar presupuestos sociales mandevillianos con una situación cosmopolita, unificar la legislación que afecta a las personas privadas como propietarios y la que se refiere a ellos como hombres libres. ${ }^{60}$ La publicidad se mantendría mientras la escisión sujeto empírico-inteligible pueda apoyarse en los presupuestos sociales del modelo liberal: el desdoblamiento bourgeois-homme-citoyen, la mano invisible de la sociedad burguesa, el orden natural. En el camino del progreso, que es el de la humanidad, la publicidad mediaría entre la razón y las coincidencias empíricas (y esto es lo que criticará implacablemente Hegel) ${ }^{61}$ De ahí que, como se ha podido advertir, haya dos "versiones" de la filosofía política en Kant: la construcción de un orden universal que supere el enfrentamiento natural, donde se hace posible la política moral desde la obligación y las leyes positivas, garantizadas por la publicidad, y una segunda en que la política ya no es entendida de un modo moral, al menos no sólo moral, sino que remite a una voluntad general que es única por el fin del público: el bienestar. Esa voluntad precisará también de la publicidad. ${ }^{62}$ Evidentemente, lo que subyace es una muy específica noción de libertad que, como ha señalado Bobbio, ${ }^{63}$ aparece tanto detrás de la definición del derecho, libertad negativa, libertad liberal como ausencia de coacción, ${ }^{64}$ como de los fines del Estado, que garantiza la libertad, no la felicidad: por eso la salus publica, como veíamos, es la construcción que garantiza la libertad a cada uno mediante la ley, la libertad privada. Precisamente eso es lo que le separa del Estado paternalista, despótico, eudemónico, que pretende proporcionar la felicidad a sus súbditos y por ello los tiraniza. El ideal de Kant es el de Federico: "en mi reino cada quien busca la felicidad a su modo", o como escribe Kant en una carta a Jung-Stilling (III, 1789): "la mejor forma de gobierno no es aquella con la que se puede vivir más agradablemente, sino aquella

\footnotetext{
60 Habermas, op. cit., pp. 144-145.

61 Ibid., p. 149.

62 Ibid., pp. 147-148.

63 En el vol. cit. en la nota 16, pp. 116-117. Bobbio, sin embargo, no acaba de advertir la contradicción entre dos modelos de filosofía politica que advierte Habermas.

64 Cfr. por ej., Rechtalehre, Einleitung, B (Was int Recht?), Werke, IV, p. 334, y I. Teil, 1 , esp. 1 y 5, pp. 353 y 357 : definición de la propiedad, y de 10 mío y lo tuyo exterior.
} 
en la que el derecho del ciudadano está mejor garantizado" ${ }^{65} \mathrm{y}$, por último, de su concepción de la historia, de la noción de progreso.

En cualquier caso, y con tales limitaciones, es a Kant a quien se debe la formulación depurada de la exigencia de publicidad, como intento de conciliación entre política y moral, y como criterio ético en política, que ocupa el lugar del imperativo de universalización de la propia acción.

65 La cita corresponde a las Lose Blätter, E 29, en Kant, Gesammelte Schriften, ed. de la Akademie der Wissenschaften, Berlín, de Gruyter, 1955, Tomo XXIII, pp. 257-260. 